\title{
Nuclear Orphan Receptor
}

National Cancer Institute

\section{Source}

National Cancer Institute. Nuclear Orphan Receptor. NCI Thesaurus. Code C20036.

Transcription factors in the nuclear receptor superfamily for which a natural lig and has not been identified. 